\title{
Optimization of Wear Properties in Aluminum Metal Matrix Composites using Hybrid Taguchi-GRA-PCA
}

\author{
Narinder Kaushik* and Sandeep Singhal \\ Department of Mechanical Engineering, National Institute of Technology, Kurukshetra, Haryana-136119, India
}

\begin{abstract}
The present work is based on the formation of aluminum alloy AA6063/SiC metal matrix composites by an enhanced liquid metallurgy stir casting route and optimization of wear properties by utilizing Taguchi based GRA integrated with a PCA

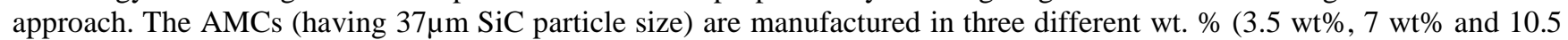
$\mathrm{wt} \%$ ) of $\mathrm{SiC}$ reinforcement particles. The exploratory runs to examine the wear performance are executed as per $\mathrm{L}_{9} \mathrm{Taguchi}$ plan to acquire the wear information in a controlled way. The wear loss data in terms of height loss is acquired using pin-ondisc tribometer attached to LVDT arrangement. Impact of three control factors, viz, Load (N), Sliding distance (m) and Wt. $\%$ of $\mathrm{SiC}$ on performance characteristics such as wear rate, frictional force and specific wear rate in dry slippery conditions are inspected to obtain the optimum level of process parameters. ANOVA is likewise completed to assess the impact of three control factors on wear rate, frictional force, and specific wear rate. Experimental analysis revealed that the wear behavior enhanced under optimum experimental states. Optical microscopic examinations of the worn-out samples are also conducted to describe the wear mechanism of the as-cast matrix composites.
\end{abstract}

Keywords: wear; AA6063; AMC (Aluminum Matrix Composite); SiC; taguchi; GRA; PCA

(Submitted on February 2, 2018; Revised on March 15, 2018; Accepted on April 19, 2018)

(C) 2018 Totem Publisher, Inc. All rights reserved.

\section{Introduction}

Metal matrix composites (MMCs) are manufactured by the introduction of very hard ceramic particles, like titanium carbide, silicon carbide, boron carbide, titanium carbide, aluminum oxide, etc. into al-compounds to achieve improved mechanical properties when compared with monolithic al-compounds. MMCs (metal matrix composites) fortified with ceramic agents have a great scope of use in automotive components, aerospace applications, defense applications, electronic parts, architectural components, etc. These manufactured composite materials are lightweight and have better hardness, which makes them wear resistant structural material in stack conveying applications. MMCs are manufactured to fulfill the demand of lightweight materials supported by high specific strength, excellent wear resistance and high stiffness [26, 17, 12]. The properties of an aluminum compound like low density, lightweight, simple assembling technique and great mechanical properties favor it as a base material in MMCs [13]. The wear examination of the AA6061+SiC composite, when subjected to normal applied load and temperature, demonstrated that wear rate lessens with expansion in applied load [30]. The dry sliding wear examination of al-matrix alloy strengthened with silicon carbide whiskers (from $0 \%$ to $16 \%$ ) detailed that the wear rates of the manufactured composite gradually decrease with an increase in vol. $\%$ of SiC whiskers into the matrix compound [8]. The impact of hardness on the wear examination of AA7075/20 vol. $\% \mathrm{Al}_{2} \mathrm{O}_{3}$ composite material demonstrated that the protection from wear of the composite material is increased by the inclusion of $20 \mathrm{vol}$. \% of SiC ceramic agents to a large extent [24]. The phenomenon of wear arises when a tough irregular surface slips over a smooth and delicate surface, bringing about material loss. The occurrence of wear is specifically obvious in automotive parts, architectural components, agricultural goods, and Earth mover units. 
It has been reported that the grating wear rate of AA2124 composites reinforced with SiC particles was increased with an increase in applied normal loads. The matrix composites reinforced with SiC grating particles demonstrated higher wear rate than those reinforced by $\mathrm{Al}_{2} \mathrm{O}_{3}$ particles because of the higher hardness of $\mathrm{SiC}$ abrasives [9]. It was detailed that $\mathrm{AA} 2104$ matrix composites reinforced with $\mathrm{Al}_{2} \mathrm{O}_{3}$ particles have shown lower wear rate for all experimental states compared to the unreinforced AA2104 matrix alloy. The work hardening phenomenon experienced by the matrix phase and the dispersion of hard $\mathrm{SiC}$ agents were responsible for low wear rate [18]. The abrasive wear rate of $\mathrm{Al}-0.86 \mathrm{Mg}-0.46 \mathrm{Si}-0.15 \mathrm{Cu}+\mathrm{Al}_{2} \mathrm{O}_{3}$ composites examined against $125 \mathrm{~mm}$ grating paper was higher when compared with the wear rate obtained when $65 \mathrm{~mm} \mathrm{SiC}$ grating paper was used. Aluminum compounds reinforced with bigger $\mathrm{Al}_{2} \mathrm{O}_{3}$ particle size have been found to be more significant against grating wear than those with small sized $\mathrm{Al}_{2} \mathrm{O}_{3}$ particles [29]. The statistical strategies have usually been utilized for investigation, forecast, and advancement of various engineering operations. Such techniques empower the researchers to characterize and think about the impact of each and every condition feasible in an analysis, especially when various components are included. The multi-objective Taguchi based grey relational analysis (GRA) has been utilized by many researchers for the optimization of wear performance in aluminum matrix composites [21].

Sahin and Ozdin [20] utilized a factorial plan of trials to create linear equations for anticipating wear rate of AA2011+SiC composites. The trial conditions showed that 10 and $15 \mathrm{wt} \% \mathrm{SiC}$ composites have higher wear oppose than that of the unreinforced AA2011 al-alloy. The wear rate of both reinforced matrix composites and unreinforced al-alloy increased with an increase in grating size and normal load, but lowered with an increase in sliding distance. The reinforcement particle size followed by normal load was observed to be the most significant parameter among other various parameters. The applied load was the predominant parameter accompanied by particle size in case of the unreinforced alloy. The interaction between grating particle size and the normal load was observed to be more remarkable for both composites and unreinforced alloy. Kok [14] utilized the Taguchi strategy to explore the grating wear conduct of AA2024 matrix composite fortified with $\mathrm{Al}_{2} \mathrm{O}_{3}$ particle under various experimental states. The results demonstrated that fortification particle size was observed to be the most influential component on grating wear, accompanied by grating particle size. For the prepared composites, the wear rate increased with an increase in grating particle size and normal load, while it reduced with an increase in fortification size and sliding distance. Suresha and Sridhara [25] researched the dry sliding wear conduct of Al- Si7Mg composites strengthened with graphite and $10 \% \mathrm{SiC}$ particles. Utilizing a central composite plan, the impact of $\%$ fortification, sliding velocity, sliding distance and normal load on wear performance of stir cast AA+graphite, AA+SiC composite, and AA+SiC+Gr hybrid composites were examined. The results demonstrated that hybrid composites demonstrated better wear qualities. Sahoo and $\mathrm{Pal}$ [21] considered the wear performance of electroless Ni- P coatings and optimized the wear test variables utilizing Taguchi technique combined with grey relational analysis (GRA). GRG (grey relational grade) acquired from GRA has been applied as a performance indicator to examine the performance of electroless $\mathrm{Ni}-\mathrm{P}$ coating regarding friction and wear qualities.

In the present research study, Taguchi L $\mathrm{L}_{9}$ orthogonal array coupled with GRA-PCA approach is used to investigate the wear behavior of the fabricated composites. Investigations are carried out for AA6063 al-alloy matrix composites reinforced with three different wt. \% (3.5\%, $7 \%$ and 10.5\%) of SiC particles. The three control variables selected in this work are Wt. \% $\mathrm{SiC}$, Normal Applied Load, and Sliding distance. The effects of these three process parameters on the performance characteristics such as wear rate, frictional force, and specific wear rate are analyzed to acquire the optimal level of the process variables. ANOVA is also carried out to obtain the contribution of each variable towards the performance characteristics. The worn surface morphology analysis of the worn out fabricated composite specimens is done to describe the wear mechanism.

\section{Experimental method}

\subsection{Materials and Methods}

In this test work AA6063 al-matrix alloy, hard and tough $\mathrm{SiC}$ reinforcement particle and $\mathrm{Mg}$ metal powder are utilized as base raw materials to produce aluminum matrix composites. Magnesium (0.45-0.9\%) and Silicon $(0.2-0.6 \%)$ are the primary alloying components in AA6063 (i.e. Mg-Si compound). The other alloying components are iron (0.35\%), copper (0.1\%), manganese $(0.1 \%)$, zinc $(0.1 \%)$, titanium $(0.1 \%)$, and chromium $(0.1 \%)$. The AA6063 matrix alloy is utilized in several fields like architectural components, irrigation piping due to excellent corrosion resistant properties, railway parts, and general engineering applications. Silicon carbide $(\mathrm{SiC})$ in particulate form was utilized as a strengthening agent. SiC is utilized as a part of many fields, like in auto brakes, grips and the electronic industry for making LEDs and locators.

The upgraded double step fluid preparing stir casting strategy has been used for the development of AA6063/SiC matrix composites explored by Fatile et al. [3] and Alaneme and Aluko [1]. An electric resistance furnace was utilized to liquefy the matrix alloy. The melting was completed under an inert atmosphere using argon gas. Al-alloy AA6063 was placed into a graphite crucible inside the furnace and was liquefied up to a temperature of $810{ }^{\circ} \mathrm{C}$ to guarantee the total liquefying of the matrix alloy. At this stage, preheated (in a separate furnace) $\mathrm{SiC}$ particles at a temperature of $900{ }^{\circ} \mathrm{C}$ were fused at a uniform rate into the liquid dissolve and dynamic mixing at 450rpm was completed to shape a fine vortex as revealed by Hashim et al. 
[6] and Sevik and Kurnaz [22]. To improve the wettability of the slurry, magnesium metal powder (1\% by wt.) was introduced into the liquid slurry during vortex mixing. Dynamic mixing of the liquid slurry was completed utilizing a graphite impeller for 15 minutes at a normal speed of $450 \mathrm{rpm}$ to assure total mixing of the reinforcement $\mathrm{SiC}$ particles into the liquid metal. Two-stage mixing technique was utilized to ensure complete mixing and to overcome the issues of agglomeration of fortification particles into the liquid slurry. The composite slurry at this stage was heated up to a temperature of $750 \pm 30{ }^{\circ} \mathrm{C}$ as the temperature drops down during mixing. The mechanical torque was again applied by a stirrer and the composite slurry was mixed for 5 minutes at $450 \mathrm{rpm}$. The Composite slurry (3.5\%, 7\%, and $10.5 \mathrm{wt}$. \%) was then solidified into a preheated $\left(\right.$ at $250^{\circ} \mathrm{C}$ ) cast iron mold to get a rectangular as-cast composite specimen. The SEM/OM images of AA6063/SiC matrix composite reinforced with $10.5 \mathrm{wt}$. SiC are shown in Figure 1.

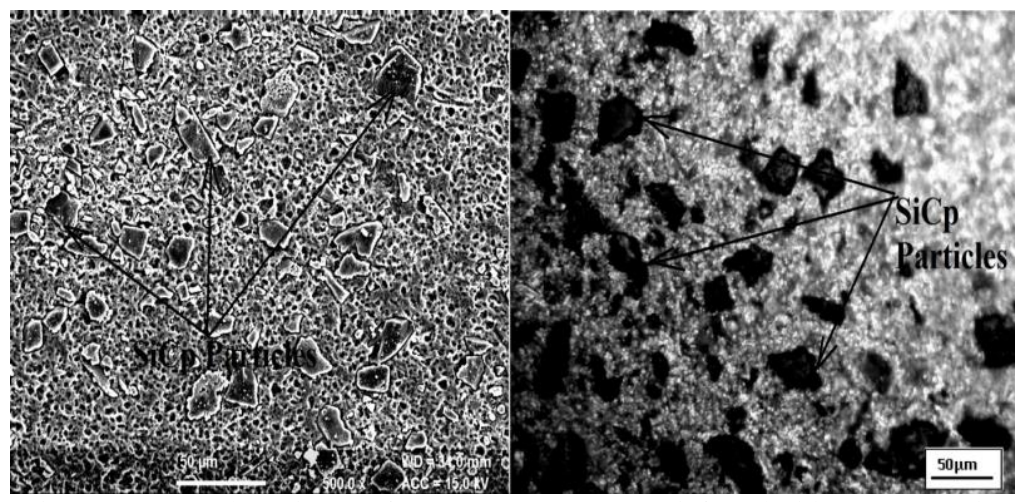

Figure 1. SEM and OM image of as-cast AA6063 AMC reinforced with 10.5 wt. \% SiC

\subsection{Pin on disc wear examinations}

The wear examinations on matrix composite samples strengthened with $3.5 \%, 7 \%$, and 10.5 wt. \% were performed in dry slippery conditions using a pin-on-disc tribometer [DUCOM (TR-20LE)]. The test set up was comprised of a rotary plate made of EN-31 steel with a hardness estimation of 62HRC. The rotary plate has $100 \mathrm{~mm}$ diameter and10mm thickness as shown in Figure 2 (a-b). Pin-on-disc tribometer was microprocessor controlled, in which height loss and frictional force were recorded simultaneously. The rectangular pin test specimens (figure 3) of size $32 \mathrm{~mm}$ x $6 \mathrm{~mm}$ x $6 \mathrm{~mm}$ were pressed against the counterface rotating plate. A load lever was swiveled near the load sensor with the dead weights. The specimens to be analyzed were fine-cleaned to level out before the start of the wear investigation and fixed against the rotary counter face plate. Composite samples were subjected to dry slippery wear tests at room temperature in agreement with Taguchi L 9 orthogonal array as in Table 2. Provision of LVDT (linear variable differential transformer) with the precision of $1 \mu \mathrm{m}$ throughout the wear testing persistently gained the wear data in terms of displacement (in mm) of the test specimen. Wear displacement sensor gave immediate readings of the deflection because of the load lever, which is analogous to the wear of the test samples. The wear performance is generally demonstrated as wear volume or weight reduction, and the wear rate was computed from height loss estimations by applying the formula:

\section{Volumetric loss $=$ Height loss $*$ cross sectional area of pin}

$$
\begin{gathered}
\text { Wear rate }(W R)=\frac{\text { Volumetric loss }}{\text { Sliding distance }} \frac{\mathrm{mm}^{3}}{\mathrm{~m}} \\
\text { Specific wear rate }(\mathrm{Sp} . \mathrm{WR})=\frac{\text { Wear rate }}{\text { Load }} \frac{\mathrm{mm}^{3}}{\mathrm{Nm}}
\end{gathered}
$$

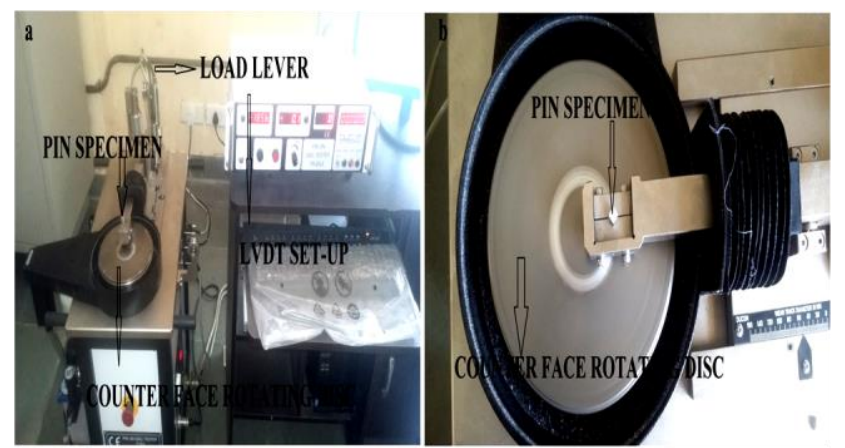

Figure 2. (a-b). Pin-on-disc wear and fiction monitor set-up 


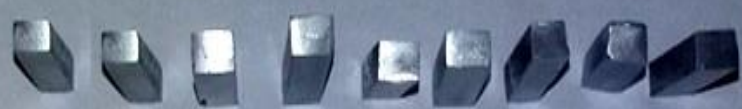 \\ $\begin{array}{llllllllll}1 & 2 & 3 & 4 & 5 & 6 & 7 & 8 & 9\end{array}$}

\section{wear test specimens}

Figure 3. Wear testing rectangular pin type specimens

Table 1. The input process factors and their levels

\begin{tabular}{|c|c|c|c|c|}
\hline \multirow[b]{2}{*}{ Sr. No. } & \multirow[b]{2}{*}{ Input process factors } & \multicolumn{3}{|c|}{ Factors at three level } \\
\hline & & 1 & 2 & 3 \\
\hline 1. & Normal applied Load (L) (N) & 20 & 30 & 40 \\
\hline 2. & Sliding Distance (SD) (m) & 523 & 1046 & 1570 \\
\hline 3. & Wt. \% SiC (W) (\%) & 3.5 & 7 & 10.5 \\
\hline
\end{tabular}

Table 2. L9 Taguchi orthogonal array for experimental design

\begin{tabular}{|c|c|c|c|}
\hline Exp. No. & $\mathrm{L}(\mathrm{N})$ & $\mathrm{SD}(\mathrm{m})$ & $\mathrm{W}(\%)$ \\
\hline 1. & 1 & 1 & 1 \\
\hline 2. & 1 & 2 & 2 \\
\hline 3. & 1 & 3 & 3 \\
\hline 4. & 2 & 1 & 2 \\
\hline 5. & 2 & 2 & 3 \\
\hline 6. & 2 & 3 & 1 \\
\hline 7. & 3 & 1 & 3 \\
\hline 8. & 3 & 2 & 1 \\
\hline 9. & 3 & 3 & 2 \\
\hline
\end{tabular}

Table 3. Values of different Response characteristics

\begin{tabular}{|c|c|c|c|c|c|c|}
\hline \multirow[b]{2}{*}{ Exp. No. } & \multicolumn{3}{|c|}{ Input process factors } & \multicolumn{3}{|c|}{ Response Characteristics } \\
\hline & $\mathrm{L}(\mathrm{N})$ & $\mathrm{SD}(\mathrm{m})$ & $\mathrm{W}(\%)$ & WR $\left(10^{-3} \mathrm{~mm}^{3} / \mathrm{m}\right)$ & $\mathbf{F F}(\mathbf{N})$ & SP. WR $\left(10^{-3} \mathrm{~mm}^{3} / \mathrm{Nm}\right)$ \\
\hline 1. & 20 & 523 & 3.5 & 11.030 & 12.01 & 0.5515 \\
\hline 2. & 20 & 1046 & 7.0 & 4.486 & 3.56 & 0.2243 \\
\hline 3. & 20 & 1570 & 10.5 & 2.830 & 2.15 & 0.1415 \\
\hline 4. & 30 & 523 & 7.0 & 9.311 & 4.15 & 0.3103 \\
\hline 5. & 30 & 1046 & 10.5 & 5.194 & 8.17 & 0.1731 \\
\hline 6. & 30 & 1570 & 3.5 & 5.340 & 13.22 & 0.1780 \\
\hline 7. & 40 & 523 & 10.5 & 10.016 & 17.56 & 0.2504 \\
\hline 8. & 40 & 1046 & 3.5 & 7.580 & 19.05 & 0.1895 \\
\hline 9. & 40 & 1570 & 7.0 & 5.427 & 6.61 & 0.1356 \\
\hline
\end{tabular}

\subsection{Taguchi + GRA + PCA Hybrid technique for optimization of wear performance}

Many specialists have utilized different statistical tools for optimization of wear properties of casted composite materials. The Taguchi approach is a standout amongst the most helpful systems for single objective optimization utilized for various design problems $[4,5,16,23,27,28,15,11]$. In the present situation of quick assembly and cost lessening, complex procedures have a few quality attributes. In such circumstances, a few multi-objective optimization strategies are required and the Taguchibased grey relational analysis (GRA) integrated with PCA (principal component analysis) is utilized as a part of the present investigation. The Taguchi technique in this study has been used to draft the experimental runs based on an orthogonal array. The Taguchi technique utilizes a statistical tool of performance, recognized as $\mathrm{S} / \mathrm{N}$ ratio (signal to noise ratio) for investigating 
the results. The signal to noise ratio is an estimation of performance to generate techniques that are unresponsive to noise components in a controlled way. In the present analysis, all the response characteristics, such as wear rate (WR), frictional force (FF) and specific wear rate (SP. WR) are of "smaller-is-better" type, and therefore, the S/N (K) ratio was calculated using equation (1). The $\mathrm{S} / \mathrm{N}(\mathrm{K})$ ratio in the Taguchi technique is calculated using following equations:

$$
\begin{aligned}
& K_{i j}=-10 \log _{10}\left(\frac{1}{n} \sum_{j=1}^{n} Y_{i j}^{2}\right) \quad(\text { smaller }- \text { is }- \text { better }) \\
& K_{i j}=-10 \log _{10}\left(\frac{1}{n} \sum_{j=1}^{n} \frac{1}{Y_{i j}^{2}}\right) \quad(\text { larger }- \text { is }- \text { better }) \\
& K_{i j}=-10 \log _{10}\left(\frac{1}{n s} \sum_{j=1}^{n} Y_{i j}^{2}\right) \quad(\text { nominal }-i s-\text { better })
\end{aligned}
$$

Grey Relational Analysis (GRA): GRA was designed by Ju-Long in 1982 [10]. GRA works like a discovery idea where known and unknown components are assembled to get the optimum level of the responses. GRA utilizes normalization of values to compute GRC (grey relational coefficients) and GRG (grey relational grade). It computes the optimal process level and ANOVA is connected to forecast the optimal level of grey relational grades.

Wear rate, frictional force and specific wear rate of as-cast composite materials are important quality characteristics. Every one of these characteristics is of the "smaller-is-better" type. The initial step is to make the grey relational formation with values in the vicinity of 0 and 1 . This formation is accomplished for all three quality characteristics. For the present examination, all the chosen quality characteristics are of the class "smaller-is-better", and grey relational is generated by using Equation (4).

$$
\begin{aligned}
X_{i}^{*}(k) & =\frac{\max X_{i}^{o}(k)-X_{i}^{o}(k)}{\max X_{i}^{o}(k)-\min X_{i}^{0}(k)} \quad(\text { smaller is better }) \\
X_{i}^{*}(k) & =\frac{X_{i}^{o}(k)-\min X_{i}^{o}(k)}{\max X_{i}^{o}(k)-\min X_{i}^{o}(k)} \quad(\text { larger is better })
\end{aligned}
$$

In the above equations $(4,5) i=1$ to $m$ and $k=1$ to $n$; $m$ is the number of experimental runs and $n$ is the number of process factors. The term $X_{i}^{o}(k)$ represents the original or reference sequence; $\min X_{i}^{0}(k)$ and $\max X_{i}^{o}(k)$ represents the minimum and maximum values in the original sequence; $X_{i}^{*}(k)$ represents the sequence produced after data processing.

The grey relational coefficients after data processing were calculated with the particular deviation calculations as given in Equations (6) and (7) [10,2]:

$$
\begin{gathered}
\Delta_{o i}(k)=\left|X_{o}^{*}(k)-X_{i}^{o}(k)\right| \\
\xi_{i}(k)=\frac{\Delta_{\min }+\psi \cdot \Delta_{\max }}{\Delta_{o i}(k)+\psi \cdot \Delta_{\max }}
\end{gathered}
$$

Where $\Delta_{o} i(k)$ is the deviation sequence of original reference sequence of $X_{o}^{*}(k)$ and the compatibility sequence $X_{i}^{o}(k)$; $\psi$ is the distinguishing coefficient and is usually 0.5 when equal weightage is given to the process parameters.

The Grey relational coefficient (GRC) for all experimental runs of the $\mathrm{L}_{9}$ orthogonal array was computed using Equation (7). In the final step of computation, the grey relational grade was calculated using Equation (8) [10, 2]. GRG is the average summation of GRCs. Before computing the GRG, PCA is integrated with GRA and it takes into consideration the weight of each response characteristic, which is multiplied with the grey relational coefficient of that performance characteristic. The value of GRG lies between 0 and 1. The larger value of GRG reveals better relation among process factors combination at that level, and it is assessed as an optimum level. 


$$
\gamma_{i}(G R G)=\frac{1}{n} \sum_{k=1}^{n} \xi_{i}(k)
$$

In Equation (8), $\gamma_{\mathrm{i}}$ denotes GRG of ith experiment, and $n$ represents the number of performance characteristics. The higher value of grey relational grade shows that the corresponding experimental results are closer to the optimum value or normalized value. However, the effect of each factor on the system is not exactly the same in real applications. Thus, (8) can be modified as follows:

$$
\gamma_{i}(G R G)=\sum_{k=1}^{n} \omega_{k} \cdot \xi_{i}(k)
$$

In Equation (9), $\omega_{k}$ denotes the weight value of factor $k$. On the same weightage, Equation (8) and (9) are equal. In this examination, the corresponding weight values $\omega_{k}$ have been acquired from principal component analysis (PCA).

Principal Component Analysis: The principal component analysis (PCA) was invented by Pearson and Hotelling [19, 7], which explains the construction of variance and covariance of all performance characteristics by linearly integrating them. The steps involved in PCA are detailed as follows:

1. To construct variance and covariance matrix $X_{i}$, the normalized values are used as follows:

$$
\begin{aligned}
& X_{i}(j), i=1 \text { to } m, j=1 \text { to } n
\end{aligned}
$$

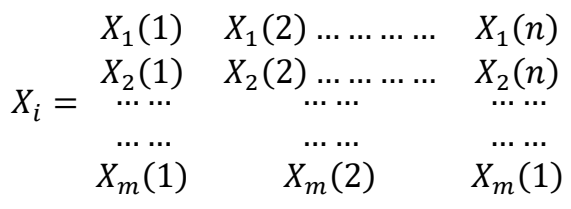

In Equation (10), $m$ denotes the number of experimental runs, and $n$ represents the number of performance or response characteristics. In this study, X represents the GRC of each performance characteristic. Here, $n=3$ and $m=9$.

2. The computation of correlation coefficient array is computed as using the following equation:

$$
R_{j l}=\left(\frac{\operatorname{cov}\left(X_{i}(j), X_{i}(l)\right)}{\sigma_{X i}(j) \times \sigma_{X i}(l)}\right) ; j=1 \text { to } n \text { and } l=1 \text { to } n
$$

In equation (11), $\operatorname{cov}\left(X_{i}(j), X_{i}(l)\right)$ are the covariance of sequences $X_{i}(j)$ and $X_{i}(l)$, respectively; $\sigma_{X i}(j)$ denotes the S.D of sequence $X_{i}(j)$, and $\sigma_{X i}(l)$ denotes the S.D of sequence $X_{i}(l)$.

3. The determination of eigenvalues and eigenvectors was done using the correlation coefficient array:

$$
\left(R-\lambda_{k} I_{m}\right) V_{i k}=0
$$

In Equation (12) $\lambda_{k}$ represents eigenvalues; $\sum_{k=1}^{n} \lambda_{k}=n$ and $k=1$ to $n$; the term $V_{i k}$ represents $V_{i k}=$ $\left[\begin{array}{lllll}a_{k 1} & a_{k 1} & \ldots & \ldots & a_{k n}\end{array}\right]^{\mathrm{T}}$ eigenvectors corresponding to eigenvalues $\lambda_{k}$.

4. The principal components: The principal components were finally computed using the following equation:

$$
y_{m k}=\sum_{i}^{n} X_{m}(i) * V_{i k}
$$

Equation (13) produces $y_{m 1}$ as the first principal component, $y_{m 2}$ as the second principal component, and so on. 


\section{Results and discussions}

\subsection{Dry sliding pin-on-disc Wear analysis}

The principal objective of the present study was to minimize wear performance characteristics such as wear rate, frictional force and specific wear rate for a casted composite matrix AA6063/SiC $\mathrm{S}_{\mathrm{p}}$ using a Taguchi-GRA-PCA hybrid optimization technique. The $\mathrm{S} / \mathrm{N}$ ratios for all three performance characteristics were computed in the first step of the analysis. As stated earlier, lower values of wear rate, frictional force, and specific wear rate produce better wear performance; so, Equation (1) has been used for the computation of $\mathrm{S} / \mathrm{N}$ ratio using MINITAB 17 software. The raw data for three performance characteristics and the corresponding $\mathrm{S} / \mathrm{N}$ ratio values are given in Table 4.

Table 4. Values of different Response characteristics

\begin{tabular}{|c|c|c|c|c|c|c|}
\hline \multirow[b]{2}{*}{ Exp. 1} & \multicolumn{3}{|c|}{ Raw data for performance characteristics/responses } & \multicolumn{2}{|c|}{$\mathrm{S} / \mathrm{N}$ ratios } & \multirow[b]{2}{*}{$\mathrm{S} / \mathrm{N}_{\mathrm{Sp} . \mathrm{WR}}$} \\
\hline & WR $\left(10^{-3} \mathrm{~mm}^{3} / \mathrm{m}\right)$ & $\mathrm{FF}(\mathrm{N})$ & Sp. WR $\left(10^{-3} \mathrm{~mm}^{3} / \mathrm{Nm}\right)$ & $\mathrm{S} / \mathrm{N}_{\mathrm{WR}}$ & $\mathrm{S} / \mathrm{N}_{\mathrm{FF}}$ & \\
\hline 1. & 11.030 & 12.01 & 0.5515 & -20.8515 & -21.5909 & 5.1770 \\
\hline 2. & 4.486 & 3.56 & 0.2243 & -17.4850 & -11.0290 & 8.5356 \\
\hline 3. & 2.830 & 2.15 & 0.1415 & -15.3134 & -6.6488 & 10.7072 \\
\hline 4. & 9.311 & 4.15 & 0.3103 & -19.3799 & -12.3610 & 10.1728 \\
\hline 5. & 5.194 & 8.17 & 0.1731 & -14.3100 & -18.2444 & 15.2391 \\
\hline 6. & 5.340 & 13.22 & 0.1780 & -14.5508 & -22.4246 & 14.9916 \\
\hline 7. & 10.016 & 17.56 & 0.2504 & -20.0139 & -23.8402 & 12.0412 \\
\hline 8. & 7.580 & 19.05 & 0.1895 & -17.5934 & -27.6223 & 14.4708 \\
\hline 9. & 5.427 & 6.61 & 0.1356 & -14.6912 & -16.4040 & 17.3548 \\
\hline
\end{tabular}

\subsection{Normalization and computation of deviation sequence}

The next step of the investigation is to normalize the data of each performance characteristic using Equation (4). The normalized values and deviation sequence are given in Table 5. The steps used in the calculation in case of experiment no. 1 are given below:

$$
\begin{aligned}
& X_{i W R}^{*}(1)=\frac{\max X_{i}^{o}(k)-X_{i}^{o}(k)}{\max X_{i}^{o}(k)-\min X_{i}^{0}(k)}=\frac{11.030-11.030}{11.030-2.830}=0 \\
& X_{i F F}^{*}(1)=\frac{\max X_{i}^{o}(k)-X_{i}^{o}(k)}{\max X_{i}^{o}(k)-\min X_{i}^{0}(k)}=\frac{19.05-12.01}{19.05-2.15}=0.4166 \\
& X_{i S p . W R}^{*}(1)=\frac{\max X_{i}^{o}(k)-X_{i}^{o}(k)}{\max X_{i}^{o}(k)-\min X_{i}^{0}(k)}=\frac{05510-0.5510}{0.5510-0.1356}=0
\end{aligned}
$$

The deviation sequence has been determined using Equation (6) for computing grey relational coefficient. The calculated normalized values and deviation sequence are presented in Table 5. The deviation sequence for exp. no. 1 is calculated as given below:

$$
\begin{gathered}
\Delta_{o i W R}(1)=\left|X_{o}^{*}(k)-X_{i}^{o}(k)\right|=|1-0|=1 \\
\Delta_{o i F F}(1)=\left|X_{o}^{*}(k)-X_{i}^{o}(k)\right|=|1-0.4166|=0.5834 \\
\Delta_{o i S p . W R}(1)=\left|X_{o}^{*}(k)-X_{i}^{o}(k)\right|=|1-0|=1
\end{gathered}
$$

\begin{tabular}{|c|c|c|c|c|c|c|}
\hline & \multicolumn{3}{|c|}{ Normalized values } & \multicolumn{3}{|c|}{ Deviation sequence } \\
\hline & WR & $\mathrm{FF}$ & Sp. WR & WR & $\mathrm{FF}$ & Sp. WR \\
\hline Exp. No. & 1.000 & 1.000 & 1.000 & 1.000 & 1.000 & 1.000 \\
\hline 1 & 0.0000 & 0.4166 & 0.0000 & 1.0000 & 0.5834 & 1.0000 \\
\hline 2. & 0.7980 & 0.9166 & 0.7865 & 0.2020 & 0.0834 & 0.2135 \\
\hline 3. & 1.0000 & 1.0000 & 0.9858 & 0.0000 & 0.0000 & 0.0142 \\
\hline 4. & 0.2096 & 0.8817 & 0.5802 & 0.7904 & 0.1183 & 0.4198 \\
\hline 5. & 0.7117 & 0.6438 & 0.9100 & 0.2883 & 0.3562 & 0.0900 \\
\hline 6. & 0.6939 & 0.3450 & 0.8979 & 0.3061 & 0.6550 & 0.1021 \\
\hline 7. & 0.1237 & 0.0882 & 0.7246 & 0.8763 & 0.9118 & 0.2754 \\
\hline 8. & 0.4207 & 0.0000 & 0.8714 & 0.5793 & 1.0000 & 0.1286 \\
\hline 9. & 0.6833 & 0.7361 & 1.0000 & 0.3167 & 0.2639 & 0.0000 \\
\hline
\end{tabular}

Table 5. Normalized data of response characteristics and corresponding Deviation sequences Reference sequence 


\subsection{Computation of GRCs and GRGs}

The grey relational coefficients were computed using the values of deviation sequence as mentioned in Table 5 by using Equation (7) for all the response characteristics. The value of $\psi=0.5$ (distinguished coefficient) was substituted in Equation (7). The grey relational grades (GRG) were calculated by using Equation (9) after incorporating the PCA approach. The computed grey relational coefficients are reported in Table 6. The example calculation for grey relational coefficient (GRC) for experiment no. 1 is given below:

$$
\begin{gathered}
\xi_{i W R}(1)=\frac{\Delta_{\min }+\psi \cdot \Delta_{\max }}{\Delta_{o i}(k)+\psi \cdot \Delta_{\max }}=\frac{0+0.5 * 1}{1+0.5 * 1}=0.3333 \\
\xi_{i F F}(1)=\frac{\Delta_{\min }+\psi \cdot \Delta_{\max }}{\Delta_{o i}(k)+\psi \cdot \Delta_{\max }}=\frac{0+0.5 * 1}{0.5834+0.5 * 1}=0.4615 \\
\xi_{i S p . W R}(1)=\frac{\Delta_{\min }+\psi \cdot \Delta_{\max }}{\Delta_{o i}(k)+\psi \cdot \Delta_{\max }}=\frac{0+0.5 * 1}{1+0.5 * 1}=0.3333
\end{gathered}
$$

Table 6. Values of different Response characteristics Grey Relational Coefficients (GRC)

\begin{tabular}{lrll} 
Exp. No. & WR & FF & Sp. WR \\
\hline 1. & 0.3333 & 0.4615 & 0.3333 \\
2. & 0.7123 & 0.8570 & 0.7007 \\
3. & 1.0000 & 1.0000 & 0.9724 \\
4. & 0.3875 & 0.8086 & 0.5436 \\
5. & 0.6343 & 0.5840 & 0.8474 \\
6. & 0.6203 & 0.4329 & 0.8305 \\
7. & 0.3633 & 0.3541 & 0.6448 \\
8. & 0.4633 & 0.3333 & 0.7955 \\
9. & 0.6122 & 0.6545 & 1.0000 \\
\hline
\end{tabular}

Principal component analysis (PCA) is introduced in GRA to exhibit the respective significance for each performance characteristics. The weighted values for each performance characteristic are determined by introducing PCA. The components of the array for the multiple performance characteristics recorded are in Table 6, which shows GRCs of each performance characteristics. These values are utilized to assess the correlation coefficient matrix and to calculate the corresponding eigenvalues using Equation (12), and they are listed in Table 7. The eigenvector relating to every eigenvalue is recorded in Table 8 , and the weighting contribution of each performance characteristic is obtained by the square of the principal component values of the corresponding eigenvectors. The contribution of individual performance characteristics, such as wear rate (WR), frictional force (FF) and specific wear rate (SP. WR), are mentioned in Table 9. Additionally, the variance contribution for the first principal component characterizing the three performance characteristics is as high as $67.9 \%$, as mentioned in Table 7. The computation of grey relation grades (GRGs) after introducing PCA and the weighted value of each performance characteristic have been obtained by using Equation (9). The GRGs and their ranks are mentioned in Table 10. The sample calculation for GRG for experiment no. 1 is given below:

$$
\gamma_{i}(G R G)=\frac{1}{n} \sum_{k=1}^{n} \xi_{i}(k)=\frac{1}{3}(0.461 * 0.3333+0.198 * 0.4615+0.341 * 0.3333)=0.1196
$$

Table 7. Eigenvalues and explained variation

\begin{tabular}{lcc} 
& Table & Eigenvalues and explained variation \\
\hline Principal component & Eigenvalue & Explained variation $(\%$ \\
\hline PC1 & 2.0213 & 67.9 \\
PC2 & 0.8562 & 28.5 \\
PC3 & 0.1224 & 4.10 \\
\hline
\end{tabular}

Table 8. Eigenvectors for principal components

\begin{tabular}{lccc}
\hline & \multicolumn{3}{c}{ Eigenvector } \\
Performance characteristic & PC1 & PC2 & PC3 \\
\hline WR & 0.679 & -0.061 & -0.732 \\
FF & 0.445 & 0.827 & 0.344 \\
SP. WR & 0.584 & -0.559 & 0.589 \\
\hline
\end{tabular}


Table 9. Contribution of the respective performance characteristic for the principal components

\begin{tabular}{lc}
\hline Performance characteristic & Contribution / Weighted value \\
\hline WR & 0.4610 \\
FF & 0.1980 \\
SP. WR & 0.3410 \\
\hline
\end{tabular}

\begin{tabular}{|c|c|c|}
\hline Exp. No. & Grey Relational Grades (GRG's) & Rank \\
\hline 1. & 0.1196 & 9 \\
\hline 2. & 0.2457 & 3 \\
\hline 3. & 0.3302 & 1 \\
\hline 4. & 0.1747 & 7 \\
\hline 5. & 0.2323 & 4 \\
\hline 6. & 0.2183 & 5 \\
\hline 7. & 0.1525 & 8 \\
\hline 8. & 0.1836 & 6 \\
\hline 9. & 0.2509 & 2 \\
\hline
\end{tabular}

All the grey relational grades values arbitrarily vary in the vicinity of 0 and 1 . A strong connection is exhibited between the reference sequence and comparability sequence as the value of GRG is approached towards the maximum.

\subsection{Evaluation of optimal combination of input process factors and their levels}

To estimate the optimum level of process factors for wear rate (WR), frictional force (FF) and specific wear rate (SP. WR), the average value of grey relation grade for each level of process factors was evaluated by utilizing the main effects examination of the Taguchi approach, and the maximum value was chosen for each factor. The GRG values analogous to three levels of input process factors and the main effects in terms of GRG have been mentioned in Table 11. In Table 11, the highlighted bold values of grey relation grade depict the highest values for the three levels of each process factor. These values correspond to Normal applied load (L) 20N, Sliding distance (SD) 1570m, and Weight \% SiC (W) $10.5 \%$ for better response characteristics as depicted in Figure 4. The optimal values of process factors yield the maximum values of grey relation grade as reported in Figure 5.

Table 11. Main effects table for GRG

\begin{tabular}{|c|c|c|c|c|c|c|c|}
\hline \multirow[b]{2}{*}{ Process factors } & \multirow[b]{2}{*}{ Symbols } & \multicolumn{3}{|c|}{ Grey relational grade } & \multicolumn{2}{|c|}{ Main effects } & \multirow[b]{2}{*}{ Rank } \\
\hline & & L1 & $\mathrm{L} 2$ & L3 & L2-L1 & L3-L2 & \\
\hline Normal Applied Load & $\mathrm{L}$ & $0.2318 *$ & 0.2084 & 0.1957 & -0.0234 & -0.0127 & 3 \\
\hline Sliding Distance & SD & 0.1489 & 0.2205 & $0.2665^{*}$ & 0.0707 & 0.0460 & 1 \\
\hline Weight $\% \mathrm{SiC}$ & $\mathrm{W}$ & 0.1738 & 0.2238 & $\mathbf{0 . 2 3 8 3}^{*}$ & 0.0500 & 0.0145 & 2 \\
\hline \multicolumn{8}{|c|}{${ }^{*}$ Optimum level of the factors $=\mathrm{L}_{1} \mathrm{SD}_{3} \mathrm{~W}_{3}$} \\
\hline
\end{tabular}

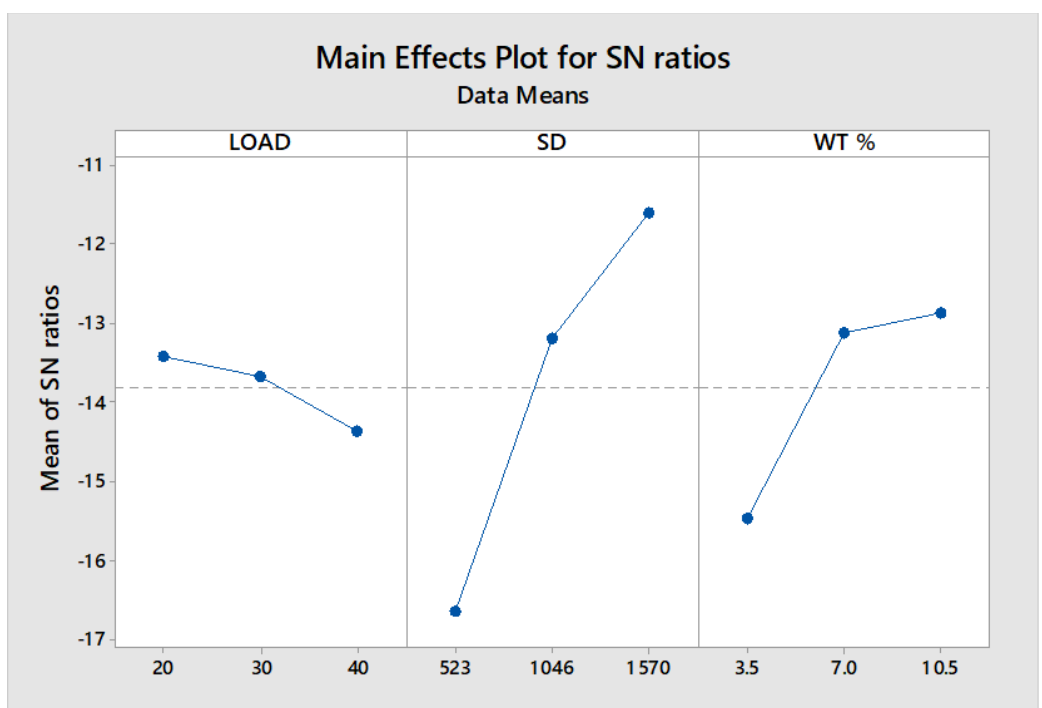

Figure 4. Graph showing S/N ratio of performance characteristics. 


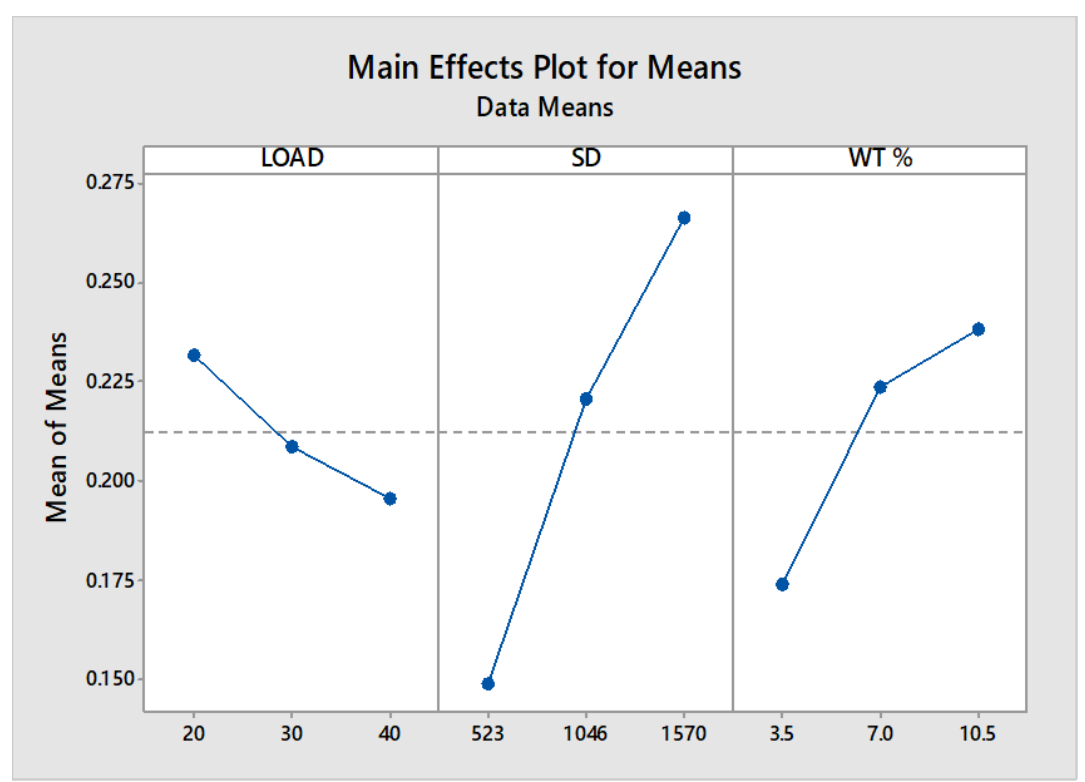

Figure 5. Graph showing main effects of grey relational grade on process parameters

\subsection{Execution of ANOVA to analyze the effect of input process factors on performance characteristics}

ANOVA has been carried out to analyze significance and contribution of each process factor to the GRG value. The ANOVA computation in Table 12 depicts the F-ratio value and \% age contribution of each process factor for the combined response of wear rate, frictional force, and specific wear rate. It can be analyzed from the ANOVA calculation table that the process factor Sliding distance (SD) and $\mathrm{Wt}$. \% SiC (W) have a 67.16 and 21.91 percentage contribution respectively and are the most significant factors minimizing the wear rate, frictional force and specific wear rate. This is followed by the factor Normal applied load, which has a $6.42 \%$ contribution towards the process.

Table 12. ANOVA calculation for GRG

\begin{tabular}{lcccc}
\hline Process factors & D.O.F & SS & MS & $\begin{array}{c}\text { F-ratio } \\
\text { Percentage Contribution (PC) } \\
(\%)\end{array}$ \\
\hline L & 2 & 0.002014 & 0.001007 & 6.42 \\
SD & 2 & 0.021057 & 0.010529 & 1.43 \\
W & 2 & 0.006870 & 0.003435 & 4.91 \\
Error & 2 & 0.001413 & 0.000706 & 21.91 \\
Total & 8 & 0.031354 & & \\
$\mathrm{~S}=0.0265772$ & & $\mathrm{R}^{2}=95.49 \% \quad \mathrm{R}^{2}(\mathrm{adj})=81.98 \%$ & \\
\hline
\end{tabular}

The regression of Equation (14) for the developed mathematical model is given below.

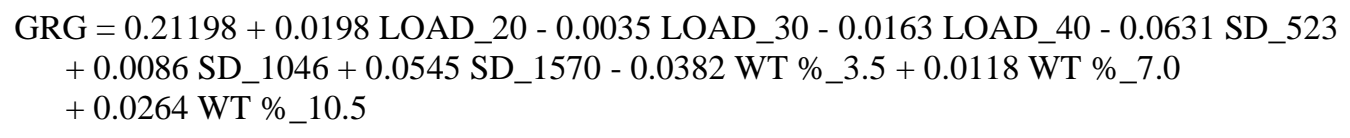

\subsection{Effect of process parameters on wear behavior}

The effect of various process parameters on the selected output parameters in terms of grey relational grade (GRG) is presented in Figure 5 and Table 11. The GRG reflects the impact of Load, Sliding distance (SD) and Wt. \% SiC on the performance characteristics. The effect of each process parameter of wear performance on the grey relational grade at different levels can be separated out, and the optimal level is described. The larger GRG value corresponds to the high-quality performance. From the main effects table and main effects plot for GRG (Table 11 and figure 5), the optimal set of the process parameter is described as $\mathrm{L}_{1} \mathrm{SD}_{3} \mathrm{~W}_{3}$. This optimal set of the process parameter is explained as Load at the $1^{\text {st }}$ level (20N), Sliding distance at the $3^{\text {rd }}$ level $(1570 \mathrm{~m})$ and $\mathrm{Wt} . \% \mathrm{SiC}$ at the $3^{\text {rd }}$ level $(10.5 \%)$. The ANOVA table (Table 12) clearly indicates that the sliding distance is the most influential parameter, followed by wt. \% and load towards process optimization.

The effect of individual parameters on dry sliding wear performance is presented in Figure 5. From Figure 5, it is shown that the wear performance of the composites is increased with an increase in sliding distance and wt. \% SiC, and decreased 
with an increase in normal applied load. It is observed from Figure 5 that with an increase in normal load, a decrease in GRG value is listed. When the load is increased from $20 \mathrm{~N}$ to $40 \mathrm{~N}$, the GRG value decreased, which resulted in poor wear performance. Due to an increase in load, the contact pressure on the sliding surface increased, which resulted in more wear at increased loads. At higher loads, the amount of heat generated increased, and plastic deformation took place at the pin surface, which resulted in a higher material removal rate and adversely affected the wear performance. The wear performance of the composites is found to be satisfactory at a lower load $(20 \mathrm{~N})$.

The sliding distance is observed to be the most influential parameter, with a 67.16 percentage contribution towards the process during dry sliding wear behavior. It is clear from Figure 5 that the GRG value increased with an increase in sliding distance. As the sliding distance increased from $523 \mathrm{~m}$ to $1570 \mathrm{~m}$, the sliding time also increased. As a result, the selflubrication phenomenon (formation of the oxide layer) and clogging of wear debris between pin and counterface disc arises. The combined effect of weir debris and the thin oxide layer leads to the formation of a mechanically mixed layer, which reduces the material removal rate from the specimen surface and enhances the wear performance of the composite.

The wear performance of the cast composites enhanced with an increase in Wt. \% of SiC reinforcement particles as shown in Figure 5. It is observed that the GRG value increased with an increase in weight percentage of $\mathrm{SiC}$ particles from $3.5 \%$ to $10.5 \%$. This is due to the existence of the hard $\mathrm{SiC}$ particles, which increased the wear resistance characteristic of the composite. The increase in weight percentage of $\mathrm{SiC}$ particles in the matrix alloy tends to increase the hardness of the alloy, which reduces the material removal rate in the composite matrix. This property of the reinforcement agent improves the wear performance of the cast composites.

\subsection{Confirmatory Test}

The confirmatory test has been conducted for the optimized settings (i.e. at $20 \mathrm{~N}$ load, $1570 \mathrm{~m}$ sliding distance and $10.5 \mathrm{wt} \%$ $\mathrm{SiC})$ to examine the accuracy of the investigation for the wear behavior of AA6063 matrix composite strengthened with different wt. \% of $\mathrm{SiC}$ reinforcement agent. After the confirmatory test, the results reported for wear behavior of the matrix

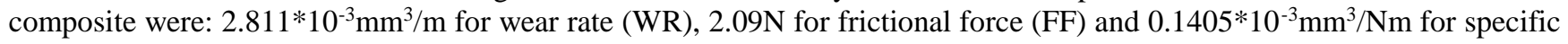
wear rate (SP. WR). The confirmation experiment results were compared with the optimum experimental values as displayed in Table 13, and an improvement in wear performance has been shown. The acquired optimized values of wear analysis process factors have been correlated with optical micrographs (OM) of the worn surface of the composite wear test specimens. During the worn surface morphology examination, the formation of fine grooves was observed to be the best combination of process variables as shown in Figure 6(a). In contrast, deep grooves and delamination of layers were observed to be the worst combination of process variables during the experimental trials as shown in Figure 6(b). The worst wear conditions during the experimental run may be reported as $10.016^{*} 10^{-3} \mathrm{~mm}^{3} / \mathrm{m}$ for wear rate, $17.56 \mathrm{~N}$ for frictional force and $0.2504 * 10^{-}$ ${ }^{3} \mathrm{~mm}^{3} / \mathrm{Nm}$ for specific wear rate at a $40 \mathrm{~N}$ normal applied load, $523 \mathrm{~m}$ sliding distance and $10.5 \mathrm{wt}$. \% SiC respectively.

\begin{tabular}{lcc} 
& Table 13. Confirmation experiment results \\
\hline Performance characteristic & $\begin{array}{c}\text { Optimum values in } \\
\text { the experimental matrix }\end{array}$ & $\begin{array}{c}\text { Values obtained with } \\
\text { optimum parameter setting }\end{array}$ \\
\hline Wear Rate $\left(\mathrm{X} 10^{-3} \mathrm{~mm}^{3} / \mathrm{m}\right)$ & 2.830 & 2.811 \\
Frictional Force $(\mathrm{N})$ & 2.15 & 2.09 \\
Specific Wear Rate $\left(\mathrm{X} 10^{-3} \mathrm{~mm}^{3} / \mathrm{Nm}\right)$ & 0.1356 & 0.1405 \\
\hline
\end{tabular}

\subsection{Worn surface morphology}

The optical microscopic examination of the worn surfaces of the AA6063 matrix composite wear test samples at different conditions is shown in Figures 6 and 7. During the wear testing, as the matrix composite surface contacts the rotating disc, wear progresses by the grooving action. A lot of scratches and cracks were seen on the worn surfaces due to the primary abrasive wear mechanism. In the optimized conditions, the formation of fine grooves and fine layers (figure 6-a) were observed. In severe wear conditions, the matrix composite observed heavy scratches and scars. The deep grooves and ploughing action was seen. These grooves were produced due to the plastic flow of matrix material, which were prompted because of the cutting or ploughing effect of the presence of hard $\mathrm{SiC}$ reinforcement agents (figure 6-b and 7). Figure 7 depicts that at a higher normal applied load of $40 \mathrm{~N}$, intense plastic deformation appeared on the ductile matrix surface, and therefore, the material removal was observed from the worn surface due to the ploughing effect. In this situation, large flakes were produced and kept along the wear path for a long time. Because of heat generation, these flakes were exposed to intense plastic deformation and expend over the wear surface. 


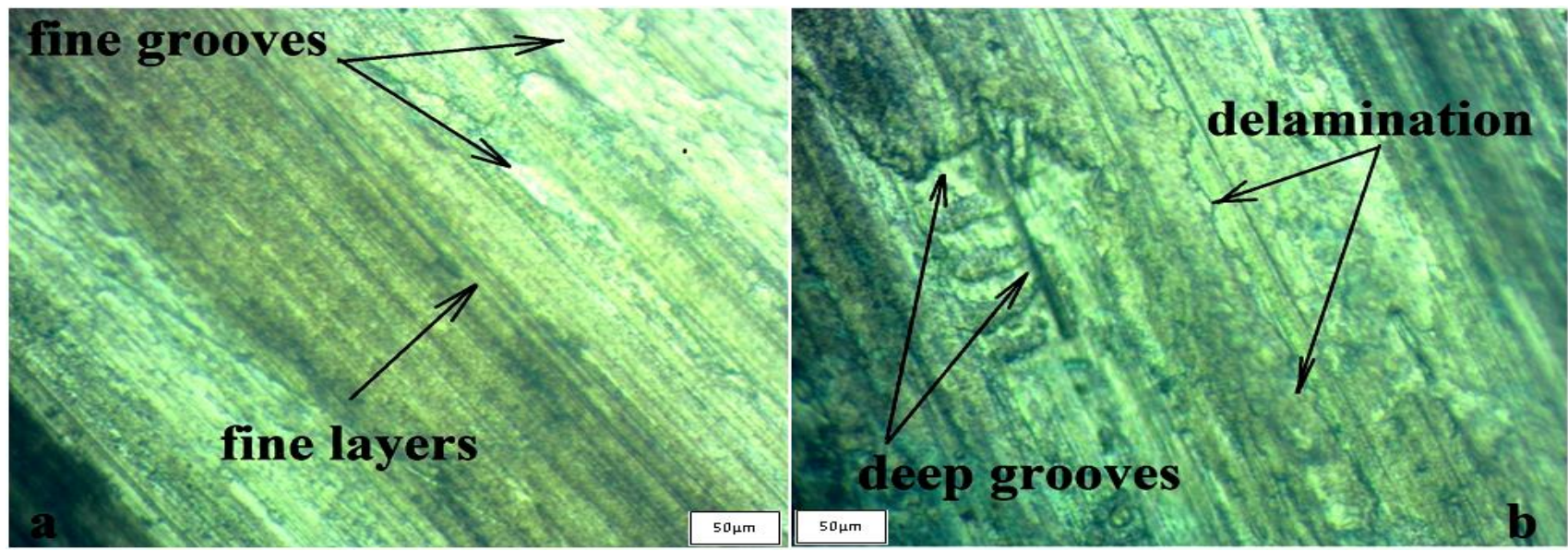

Figure 6. Worn surfaces (a) In best condition (b) In worst condition

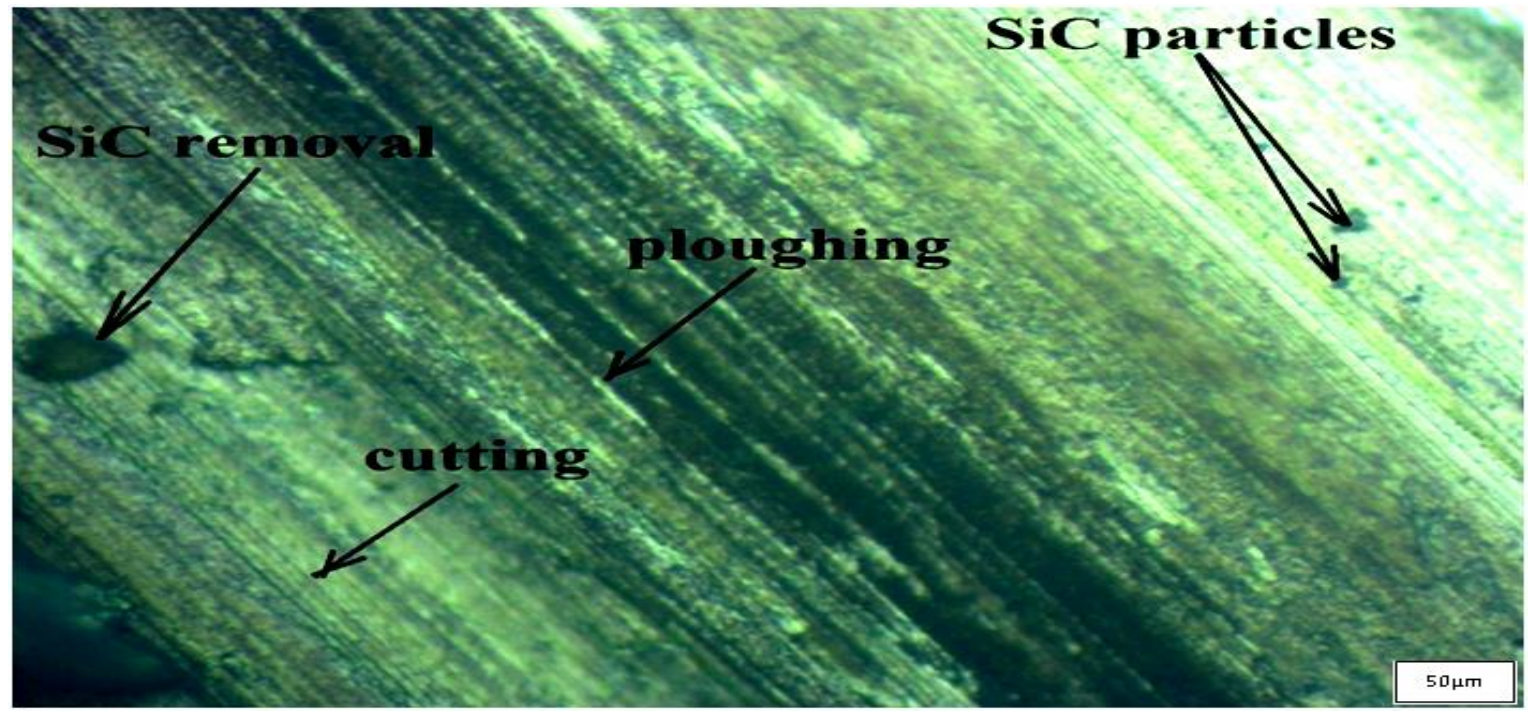

Figure 7. Worn surface of AA6063/SiC $\mathrm{AMC}$ at a Load of $40 \mathrm{~N}$, Sliding distance of $523 \mathrm{~m}$ and $10.5 \mathrm{Wt}$ \% of SiC.

\section{Conclusions}

The hybrid Taguchi-GRA-PCA approach for the optimization of wear behavior process variables has been established systematically to overcome the limitations of single objective techniques in multiple performance characteristics problems. The difficulty that occurs during the calculation for all the performance characteristics in GRA is solved by incorporating the PCA to calculate the grey relational grades. The impact of different process variables, such as normal applied load, sliding distance, and wt. \% SiC, on wear performance of the casted composite has been reported systematically using this hybrid technique. The outcomes of this work can be summarized as follows: (1) The minimization of wear rate, frictional force, and specific wear rate has been established to be an optimum variable combination of wear behavior at a normal applied load of $20 \mathrm{~N}$, sliding distance $1570 \mathrm{~m}$ and wt. $\%$ of SiC $10.5 \%$. (2) The integrated response of wear rate, frictional force, specific wear rate at a normal applied load $(\mathrm{PC}=6.42 \%)$, sliding distance $(\mathrm{PC}=67.16 \%)$ and wt. \% $\mathrm{SiC}(\mathrm{PC}=21.92 \%)$ applied a significant impact on the wear performance of aluminum matrix composites. (3) The confirmatory tests exhibit that the actual values of the performance characteristics at the optimum selection of process variables exist within the optimum experimental values. (4) The phenomenon of grooving, such as fine grooves and deep grooves, ploughing, delamination and cutting effect along the wear path during the wear test of the composite surfaces, has been successfully reported using the OM examination. (5) The al-alloy AA6063 matrix composites with $10.5 \mathrm{wt} \% \mathrm{SiC}$ reported excellent wear performance for the optimized wear variables combination.

\section{Acknowledgments}

This work was supported by the Department of Mechanical Engineering, National Institute of Technology Kurukshetra. 


\section{References}

1. Alanemea $\Psi$, Kenneth K., and Ayotunde O. Aluko, "Production and age-hardening behavior of borax premixed $\mathrm{SiC}$ reinforced Al-Mg-Si alloy composites developed by double stir-casting technique," (2012).

2. Çaydaş, Ulaş, and Ahmet Hasçalık, "Use of the grey relational analysis to determine optimum laser cutting parameters with multi-performance characteristics," Optics \& Laser Technology40.7 (2008): 987-994.

3. Fatile, Oluwagbenga B., Felix U. Idu, and Olajide T. Sanya, "Fabrication Characteristics and Mechanical Behavior of Fly Ash-Alumina Reinforced Zn-27Al Alloy Matrix Hybrid Composite Using Stir-Casting Technique," World Academy of Science, Engineering and Technology, International Journal of Chemical, Molecular, Nuclear, Materials and Metallurgical Engineering 9.10 (2015): 1215-1219.

4. Ghetiya, N. D., K. M. Patel, and A. J. Kavar, "Multi-objective optimization of FSW process parameters of aluminum alloy using Taguchi-based grey relational analysis," Transactions of the Indian Institute of Metals 69.4 (2016): 917 923.

5. Gupta, Meenu, and Surinder Kumar, "Multi-objective optimization of cutting parameters in turning using grey relational analysis," International Journal of Industrial Engineering Computations 4.4 (2013): 547-558.

6. Hashim, J., L. Looney, and M. S. J. Hashmi, "Metal matrix composites: production by the stir casting method," Journal of Materials Processing Technology 92 (1999): 1-7.

7. Hotelling, Harold, "Analysis of a complex of statistical variables into principal components," Journal of educational psychology 24.6 (1933): 417.

8. Iwai, Yoshiro, Hidetomo Yoneda, and Tomomi Honda, "Sliding wear behavior of SiC whisker-reinforced aluminum composite," Wear 181 (1995): 594-602

9. Izciler, M., and M. Muratoglu, "Wear behavior of SiC reinforced 2124 Al alloy composite in RWAT system," Journal of materials processing Technology 132.1 (2003): 67-72.

10. Ju-Long, Deng, "Control problems of grey systems," Systems \& Control Letters 1.5 (1982): 288-294.

11. Kaushik, N., \& Singhal, S, "Examination of Wear Properties in Dry-Sliding States of SIC Strengthened Al-Alloy Metal Matrix Composites by Using Taguchi Optimization Approach", International Journal of Applied Engineering Research, 12(20), 9708-9716.

12. Kaushik, Narinder \& Singhaal, Sandeep, "Mechanical and Metallurgical Examinations of Stir Cast Aluminum Matrix Composites: A Review Study," International Journal of Engineering and Technology. 9. 3203-3217. 10.21817/ijet/2017/v9i4/170904135.

13. Khan, Kirity Bhusan, T. R. G. Kutty, and M. K. Surappa, "Hot hardness and indentation creep study on Al-5\% Mg alloy matrix-B 4 C particle reinforced composites," Materials Science and Engineering: A 427.1 (2006): 76-82.

14. Kök, Metin, "Computational investigation of testing parameter effects on abrasive wear behavior of Al $2 \mathrm{O} 3$ particlereinforced MMCS using statistical analysis," The International Journal of Advanced Manufacturing Technology 52.1 (2011): 207-215.

15. Kundu, Jitender, and Hari Singh, "Friction stir welding: multi-response optimization using Taguchi-based GRA," Production \& Manufacturing Research 4.1 (2016): 228-241.

16. Kuram, Emel, and Babur Ozcelik, "Multi-objective optimization using Taguchi based grey relational analysis for micro-milling of Al 7075 material with ball nose end mill," Measurement 46.6 (2013): 1849-1864.

17. Lopez, V. H., A. Scoles, and A. R. Kennedy, "The thermal stability of TiC particles in an Al7wt.\% Si alloy," Materials Science and Engineering: A 356.1 (2003): 316-325.

18. Modi, O. P, "Two-body abrasion of a cast Al-Cu (2014 Al) alloy-Al 2 O 3 particle composite: influence of heat treatment and abrasion test parameters," Wear 248.1 (2001): 100-111.

19. Pearson, Karl, "LIII. On lines and planes of closest fit to systems of points in space," The London, Edinburgh, and Dublin Philosophical Magazine and Journal of Science 2.11 (1901): 559-572.

20. Sahin, Y., and K. Özdin, "A model for the abrasive wear behavior of aluminum based composites," Materials \& Design 29.3 (2008): 728-733.

21. Sahoo, Prasanta, and Sujan Kumar Pal, "Tribological performance optimization of electroless Ni-P coatings using the Taguchi method and grey relational analysis," Tribology letters 28.2 (2007): 191-201.

22. Sevik, Hüseyin, and S. Can Kurnaz. "Properties of alumina particulate reinforced aluminum alloy produced by pressure die casting." Materials \& design 27.8 (2006): 676-683.

23. Singh, P. Narender, K. Raghukandan, and B. C. Pai, “Optimization by grey relational analysis of EDM parameters on machining Al-10\% SiC P composites,” Journal of Materials Processing Technology 155 (2004): 1658-1661.

24. Straffelini, G., et al, "Influence of matrix hardness on the dry sliding behavior of 20 vol.\% Al 2 O 3-particulatereinforced 6061 Al metal matrix composite," Wear 211.2 (1997): 192-197.

25. Suresha, S., and B. K. Sridhara, "Wear characteristics of hybrid aluminum matrix composites reinforced with graphite and silicon carbide particulates," Composites Science and Technology 70.11 (2010): 1652-1659.

26. Tokaji, K., "Effect of stress ratio on fatigue behaviour in SiC particulate-reinforced aluminium alloy composite," 
Fatigue \& Fracture of Engineering Materials \& Structures 28.6 (2005): 539-545.

27. Tosun, Nihat, "Determination of optimum parameters for multi-performance characteristics in drilling by using grey relational analysis," The International Journal of Advanced Manufacturing Technology 28.5-6 (2006): 450-455.

28. Y.-K. Yang, J.-R. Shie, and C.-H. Huang, "Optimization of dry machining parameters for high-purity graphite in end-milling process," Materials and Manufacturing Processes, vol. 21, no. 8, pp. 832-837, 2006.

29. Yilmaz, O., and S. Buytoz, "Abrasive wear of Al 2 O 3-reinforced aluminium-based MMCs," Composites Science and Technology 61.16 (2001): 2381-2392.

30. Yu, Szu Ying, et al., "Temperature dependence of sliding wear behavior in SiC whisker or SiC particulate reinforced 6061 aluminum alloy composite," Wear 213.1-2 (1997): 21-28.

Narinder Kaushik, Research Scholar, Mechanical-Engineering, National Institute of Technology Kurukshetra. Research interests include composite materials and friction stir welding of aluminum alloy composites.

Sandeep Singhal, Doctorate, Mechanical Engineering. Associate Professor at the National Institute of Technology Kurukshetra. Research interests include SCM, ERP, TQM, entrepreneurship, facility management, etc. 